\title{
Clustering of cardiovascular risk factors among Omani adults
}

A.A. Al Riyami and M. Afifi ${ }^{1}$

$$
\begin{aligned}
& \text { تبويب عز امل الاختطار القلبية الوعائية لدى البالغين العُمانيين } \\
& \text { آسيا الزيامي ومصطفى عفيفي }
\end{aligned}
$$

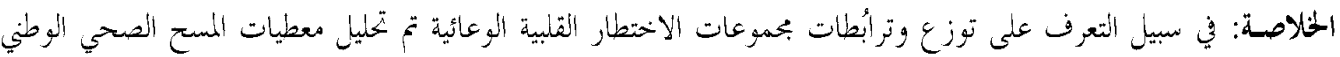

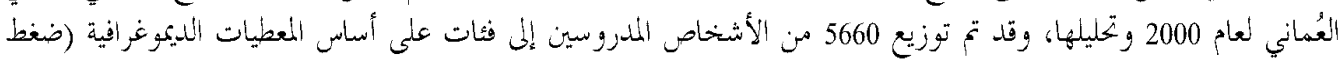

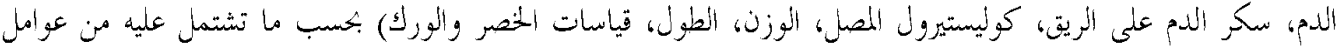

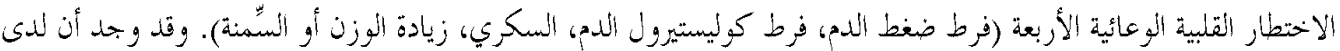

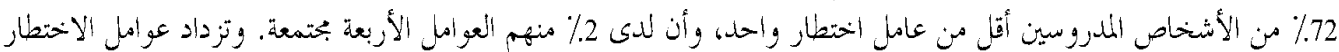

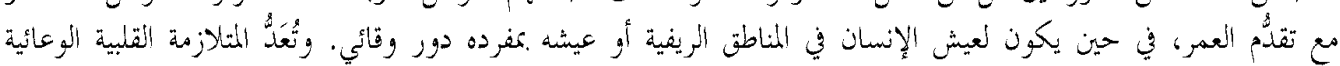

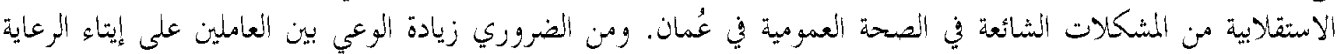

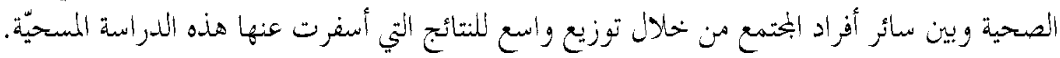

ABSTRACT To determine the distribution and correlates of clustering of cardiovascular disease (CVD) risk factors, data from the Oman National Health Survey, 2000 were analysed. Based on demographic data (blood pressure, fasting blood glucose, serum cholesterol, weight, height, waist and hip measurements), 5660 subjects were grouped according to how many of four CVD risk factors (hypertension, high cholesterol, diabetes, overweight/obesity) they had. We found that $72 \%$ of subjects had less than one risk factor and $2 \%$ had all four. Older age exacerbated risk, while living in rural areas or being single was protective. Metabolic cardiovascular syndrome is a public health problem in Oman. Increasing awareness in healthcare providers and the wider population by comprehensive dissemination of the survey results is crucial.

\section{Association des facteurs de risque cardio-vasculaire chez des adultes omanais}

RESUME Les données provenant de l'enquête nationale sur la santé réalisée à Oman en 2000 ont été analysées pour déterminer la distribution et les corrélats de l'association des facteurs de risque des maladies cardio-vasculaires. Sur la base des données démographiques (tension artérielle, glycémie à jeun, cholestérol sérique, mesures du poids, de la taille, du tour de taille et de hanches), 5660 sujets ont été groupés en fonction du nombre de facteurs de risque de maladie cardio-vasculaire qu'ils avaient parmi les quatre suivants : hypertension, cholestérol élevé, diabète, surcharge pondérale/obésité. Nous avons constaté que $72 \%$ des sujets présentaient au moins un facteur de risque et que $2 \%$ présentaient les quatre. L'âge avancé exacerbait le risque, tandis que le fait de vivre en milieu rural ou d'être célibataire constituait une protection. Le syndrome métabolique cardio-vasculaire est un problème de santé publique à Oman. La sensibilisation des prestataires de soins de santé et de la population générale par la large diffusion des résultats de l'enquête est cruciale.

${ }^{1}$ Department of Research and Studies, Ministry of Health, Oman. Received: 02/04/02; accepted: 18/08/02

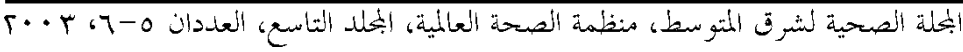




\section{Introduction}

Social advances in Oman since 1970 have been accompanied by cultural changes, a reduction in the prevalence of communicable diseases, increased life expectancy, changes in nutritional habits and habitual physical activity and increased prevalence of noncommunicable diseases such as hypertension and diabetes [1]. Environmental and behavioural changes such as the adoption of new dietary habits and a sedentary lifestyle, and the stress of urbanization and of working conditions have all contributed to the rise in cardiovascular disease (CVD) risk factors [2]. The primary risk factors for CVD are hypertension, high cholesterol, diabetes, overweight, cigarette smoking and physical inactivity. The first 4 of these may cluster in some persons and have been identified as components of a syndrome known as metabolic cardiovascular syndrome, or the "deadly quartet" [3].

Approximately $50 \%$ of hypertensive people can be considered to have insulin resistance and hyperinsulinaemia. It appears likely that insulin resistance and hyperinsulinaemia predispose to, rather than result from, hypertension. Insulin resistance is associated with abnormalities in lipoprotein metabolism, hypercoagulability, and endothelial function, which probably account in part for the increased cardiovascular risk among hypertensive patients [4]. Patients with at least 1 component of the metabolic syndrome have been found to be obese, hyperinsulinaemic, insulin resistant, hyperglycaemic, hypertensive, and dyslipidaemic [5].

The association between hyperinsulinaemia and cardiovascular risk factors has been investigated in Gulf countries. In the United Arab Emirates, Bener et al. examined the association between acanthosis negricans, hyperinsulinaemia and cardiovascular risk factors [6]. They found that patients with acanthosis negricans had a high prevalence of abnormal glucose tolerance and hyperinsulinaemia. In addition, euglycaemic patients with hyperinsulinaemia had a cluster of risk factors for CVD. In Bahrain, Musaiger and al-Roomi found that obesity, hypertension and diabetes were highly prevalent and significantly more frequently reported among women than men, with $79.6 \%$ of women overweight or obese, compared to $56 \%$ of men [7]. They also recommended the need for a national health policy to prevent and control CVD. In Egypt, Ibrahim et al. studied the clustering of CVD risk factors in hypertensive patients. They found that obesity was prevalent in 33\% of hypertensive men and $47 \%$ of hypertensive women [8]. After adjusting for age, hypertensive men had significantly higher total cholesterol, fasting blood sugar, body mass index (BMI) and waist-hip ratio than their normotensive counterparts. In addition, hypertensive women had higher low-density lipoprotein (LDL) cholesterol.

Using World Health Organization criteria (WHO) [9], the Oman National Health Survey, 2000 identified the prevalence of hypertension, high cholesterol, diabetes, overweight and obesity among Omani adults. The National Health Survey was a cross-sectional community-based study involving all 10 regions of Oman. The aim of our study was to examine the aggregation or clustering of these CVD risk factors and the correlates of this clustering among those Omani subjects aged $\geq 20$ years who had been included in the National Health Survey.

\section{Methods}

\section{Sample design and participants}

The sample for the survey was selected to be representative of the whole nation. The 
survey adopted a multistage stratified probability sampling design. All 10 regions of the country were sampled proportionally. Depending on the size of the population for each region, one or more wilayat (districts) were randomly chosen from that region, with 16 wilayat selected for the survey from a national total of 59. Each wilayat was stratified into urban or rural (villages/ remote areas), resulting in an urban:rural ratio of 2:1, similar to that of the 1993 national census. Within each of these strata, enumeration areas (EAs, census units used during the 1993 population census, each containing approximately 80 households) were randomly selected. Households within each of the EAs were then randomly selected. Maps of the selected EAs were updated, and a comprehensive listing of all Omani households in each EA was made to obtain the sampling frame.

All individuals aged $\geq 20$ years $(n=$ $7011)$ in the selected households $(n=1968)$ were invited to participate in the survey. The response rate varied from $81 \%$ to $91 \%$, according to the type of measurement or laboratory investigation completed. Of the 7011 eligible participants, 5660 (81\%) completed the questionnaire, had their blood taken to measure fasting blood glucose and completed the other necessary measurements and laboratory investigations in order to have their data analysed.

\section{Questionnaire and measurements}

The Household Health Status questionnaire covered demographic data such as age and sex, and marital, education and employment status, as well as self-reporting for diabetes mellitus and hypertension. Education status was classified into 3 groups: illiterate; those who could read and write and had completed either primary or preparatory school, or had spent some years in secondary school; and those who had completed secondary school, college, university or postgraduate tertiary studies.

Blood pressure (BP) was measured manually. This measure, together with data for weight, height, waist and hip circumference, was registered in the questionnaire. Waist-hip ratio was not considered as a variable in this analysis. WHO procedures were used to obtain the measurements [9]. The results of laboratory investigations taken for fasting blood glucose and serum cholesterol were also entered on the questionnaire. Certain important biochemical measurements related to CVD risk factors, such as high-density lipoprotein (HDL) cholesterol, LDL cholesterol, triglyceride or microalbuminuria levels were not collected during the survey.

\section{Specimen collection and analysis}

For specimen collection and analysis, 25 teams were assembled and trained in the methodology of the survey for 2 weeks. Each team consisted of a nurse to take measurements, a laboratory technician to draw samples, a health educator to interview subjects, a health inspector to transport laboratory samples and a field supervisor (statistician) to supervise and review the questionnaires in the field.

Eligible members of the selected households were requested to commence fasting 1-2 hours before midnight the night before they were to be visited by the survey team. At 07.00 the following morning, household members were interviewed, had their measurements taken and venous fasting blood glucose samples collected. Fasting blood samples for glucose were collected in sodium fluoride potassium oxalate tubes, labelled and transferred immediately in cold boxes, along with laboratory forms, to the laboratory at the wilayat hospital. Samples were immediately centrifuged, the plasma separated and fasting plasma glucose deter-

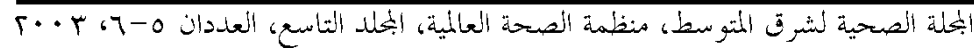


mined by a glucose oxidase method on the same day, using a Hitachi 911 automated clinical chemistry analyser (Boehringer Mannheim). The same manufacturer supplied the reagents. Samples for estimation of cholesterol were collected in tubes containing lithium heparin anticoagulants and transferred to the laboratory, where the investigations were carried out by the enzymatic colorimetric method, also using the Hitachi 911 analyser.

\section{Diagnostic criteria}

The 1999 WHO criteria [9] for diagnosis of hypertension, hypercholesterolaemia, anthropometric measurement and glucose intolerance were used.

\section{Diastolic hypertension}

Patients who self-reported being hypertensive were categorized as having diastolic hypertension (even if their blood pressure reading at the time of screening was normal) only if the interviewer either sighted their medication, or verified that the subject had been diagnosed as hypertensive by a medical practitioner. Patients were also categorized as having diastolic hypertension if the mean of two $\mathrm{BP}$ readings was $\geq 90$ $\mathrm{mm} \mathrm{Hg}$ diastolic phase 5, regardless of their systolic blood pressure readings. Hypertensive subjects were further classified in the logistic regression models as having mild hypertension (diastolic BP 90-104 $\mathrm{mm} \mathrm{Hg)} \mathrm{or} \mathrm{moderate/severe} \mathrm{hypertension}$ (diastolic BP $\geq 105$ mm Hg).

\section{Hypercholesterolaemia}

Patients were categorized as having hypercholesterolaemia if their total cholesterol level was $\geq 5.2 \mathrm{mmol} / \mathrm{L}$ or $\geq 200 \mathrm{mg} / \mathrm{dL}$.

\section{Anthropometric measurements}

Body mass index [BMI = weight $(\mathrm{kg}) /$ height ${ }^{2}\left(\mathrm{~m}^{2}\right)$ ] was classified according to the accepted norms: underweight (BMI < $\left.18.5 \mathrm{~kg} / \mathrm{m}^{2}\right)$, normal (18.5-24.9 kg/m²), overweight (25.0-29.9 $\left.\mathrm{kg} / \mathrm{m}^{2}\right)$, obese (30.0-39.9 $\left.\mathrm{kg} / \mathrm{m}^{2}\right)$ and morbidly obese $(\geq$ $40.0 \mathrm{~kg} / \mathrm{m}^{2}$ ).

\section{Diabetes mellitus}

Participants were categorized as having diabetes mellitus if they self-reported having diabetes, or their fasting blood glucose reading was $\geq 7.0 \mathrm{mmol} / \mathrm{L}$.

\section{Data processing and analysis}

Data were entered using Epi-Info, version 6.04 software. Preparation of the data was completed by July, 2000. Data were analysed using SPSS, version 9.0. Data were given as counts, means and percentages. Group means were compared using ANO$\mathrm{VA}$, and the chi-squared test examined the distribution of data using the likelihood ratio.

Step-wise logistic regression was conducted to test for the factors most strongly associated with the dependent variable under study and to obtain the adjusted odds ratio (OR) for each factor. All independent variables used in the logistic models were dichotomous (after recoding some of them to be so). The OR shows the change in the odds of the dependent variable under study when the independent variable changed from 0 to 1 . A $P$-value $<0.05$ was considered statistically significant.

\section{Results}

Table 1 shows participants' demographic and social characteristics. Males and females were equally represented, a majority (62.1\%) were aged between 20 and 39 years, $73 \%$ lived in rural areas, approximately 34\% were illiterate, and $7 \%$ were current smokers.

The 4 CVD risk factors investigated in our study were diastolic hypertension, dia- 
Table 1 Demographic and social characteristics of National Health Survey participants, Oman, 2000

\begin{tabular}{|c|c|c|}
\hline Characteristic & No. & $\%$ \\
\hline \multicolumn{3}{|l|}{ Age group (years) } \\
\hline $20-39$ & 4353 & 62.1 \\
\hline $40-59$ & 1753 & 25.0 \\
\hline$\geq 60$ & 905 & 12.9 \\
\hline Total & 7011 & 100.0 \\
\hline \multicolumn{3}{|l|}{ Sex } \\
\hline Male & 3506 & 50.0 \\
\hline Female & 3505 & 50.0 \\
\hline Total & 7011 & 100.0 \\
\hline \multicolumn{3}{|l|}{ Residence } \\
\hline Urban & 5143 & 73.4 \\
\hline Rural & 1868 & 26.4 \\
\hline Total & 7011 & 100.0 \\
\hline \multicolumn{3}{|l|}{ Education } \\
\hline Illiterate & 2333 & 33.8 \\
\hline$<$ Secondary & 2824 & 40.9 \\
\hline$\geq$ Secondary & 1753 & 25.3 \\
\hline Total & 6910 & 100.0 \\
\hline \multicolumn{3}{|l|}{ Work status } \\
\hline Working & 2778 & 39.9 \\
\hline Not working & 4191 & 60.1 \\
\hline Total & 6969 & 100.0 \\
\hline \multicolumn{3}{|l|}{ Marital status } \\
\hline Married & 4668 & 66.7 \\
\hline Not married & 2327 & 33.3 \\
\hline Total & 6995 & 100.0 \\
\hline \multicolumn{3}{|l|}{ Family size } \\
\hline$\leq 10$ members & 3696 & 52.7 \\
\hline$>10$ members & 3315 & 47.3 \\
\hline Total & 7011 & 100.0 \\
\hline \multicolumn{3}{|l|}{ Currently smoking } \\
\hline Yes & 488 & 7.0 \\
\hline No & 6515 & 93.0 \\
\hline Total & 7003 & 100.0 \\
\hline
\end{tabular}

betes mellitus, hypercholesterolaemia, and overweight/obesity. Of the 5660 subjects tested (aged 20 years and above), 25.2\% had high diastolic blood pressure, approxi- mately $11 \%$ had diabetes, $41 \%$ had a high level of serum cholesterol and $48 \%$ were overweight or obese. Only $28 \%$ of subjects had none of these CVD risk factors (i.e. $72 \%$ had at least 1 CVD risk factor), $34.8 \%$ had 1 risk factor, $24.6 \%$ had 2 risk factors, $10.6 \%$ had 3 risk factors and $2 \%$ had all 4 risk factors.

Participants were divided into 2 groups, as having either $\leq 1$ risk factor ( $63 \%$ of the study sample) or having $\geq 2$ risk factors (37\%). The dependent variable introduced in the logistic models was having (or not having) $\geq 2$ risk factors. The independent variables were gender, age group, place of residence, marital status, level of education and work status.

Table 2 shows the means of the CVD risk factors in the overall sample and the comparison of these means among groups of subjects with 0,1 , or $>1$ risk factors. The BP measurement increased steadily with clustering of risk factors. Subjects with none of the risk factors had a mean BP of 119.3/75.3 mm Hg, while those with 4 risk factors had a mean BP of 149/95.6 mm Hg (SBP measurements are not shown in Table 2). The differences between the mean values for diastolic blood pressure were significant for the groups overall and between each group, using the Tukey method $(P<0.05$ is statistically significant). The mean values for fasting blood glucose, serum cholesterol and BMI also increased significantly with the number of aggregated risk factors.

To identify the significantly associated variables with the dependent binary variable having (or not having) 2 or more risk factors, we used multiple logistic regression. From the different models, we obtained the OR for each significant independently associated variable. The independent variables included in the models were: age, sex, place of residence, marital status, and level

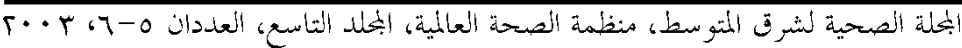




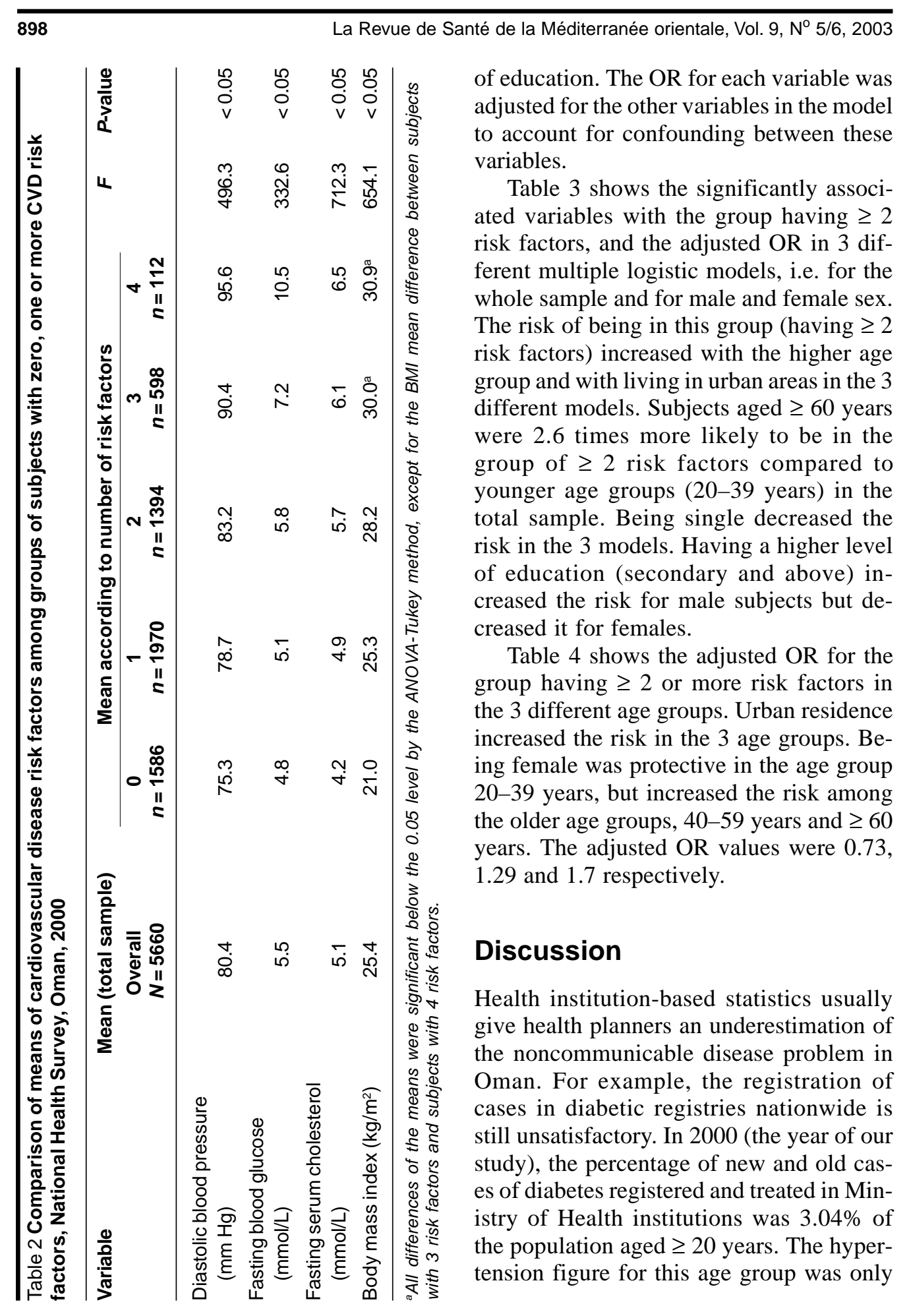

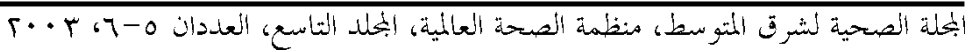




\begin{tabular}{|c|c|c|c|c|c|c|}
\hline \multirow[t]{2}{*}{ Variable } & \multicolumn{2}{|c|}{ Total $(N=5557)^{a}$} & \multicolumn{2}{|c|}{ Males $(n=2781)$} & \multicolumn{2}{|c|}{ Females $(n=2776$} \\
\hline & $\begin{array}{l}\text { Adjusted } \\
\text { OR }\end{array}$ & $P$-value & $\begin{array}{l}\text { Adjusted } \\
\text { OR }\end{array}$ & $P$-value & $\begin{array}{c}\text { Adjusted } \\
\text { OR }\end{array}$ & $P$-value \\
\hline \multicolumn{7}{|l|}{ Age group (years) } \\
\hline $20-39=1(R C)$ & 1.00 & & - & - & 1.00 & \\
\hline $40-59=2$ & 2.83 & $<0.001$ & 2.93 & $<0.001$ & 3.04 & $<0.001$ \\
\hline$\geq 60=3$ & 2.61 & $<0.001$ & 2.43 & $<0.001$ & 3.85 & $<0.001$ \\
\hline \multicolumn{7}{|l|}{ Place of residence } \\
\hline Urban $=0$ & - & - & - & - & - & - \\
\hline Rural = 1 & 0.76 & $<0.001$ & 0.75 & 0.002 & 0.76 & 0.004 \\
\hline \multicolumn{7}{|l|}{ Work status } \\
\hline Working $=0$ & - & - & - & - & - & - \\
\hline Not working $=1$ & 0.87 & 0.030 & - & - & - & - \\
\hline \multicolumn{7}{|l|}{ Education level } \\
\hline Illiterate $=1(R C)$ & - & - & 1.00 & & 1.00 & \\
\hline$<$ Secondary = 2 & - & - & 1.40 & 0.003 & 1.04 & 0.747 \\
\hline$\geq$ Secondary $=3$ & - & - & 1.87 & 0.000 & 0.69 & 0.024 \\
\hline \multicolumn{7}{|l|}{ Marital status } \\
\hline Single $=1$ & 0.38 & $<0.001$ & 0.31 & $<0.001$ & 0.50 & $<0.001$ \\
\hline Divorced/separated $=2$ & 1.22 & 0.200 & 0.82 & 0.478 & 1.51 & 0.032 \\
\hline Widowed $=3$ & 1.24 & 0.080 & 1.15 & 0.685 & 1.07 & 0.628 \\
\hline Married $=4(\mathrm{RC})$ & 1.00 & & 1.00 & & 1.00 & \\
\hline
\end{tabular}

aThe total number of subjects in the study was 7011, of whom 5660 (81\%) completed the physical and laboratory measurements. However, the data of 3 subjects (0.05\% of 5660 subjects) were not entered in the logistic regression models due to missing data in some of the independent variables. $R C=$ Reference category

4.8\% [10], whereas in our study, the prevalence of diabetes and hypertension were $11 \%$ and $25 \%$, respectively. Only by identifying the distribution and correlates of clustering of CVD risk factors in a community-based study were we able to obtain an accurate estimate of the magnitude of the problem in both urban and rural settings.

ANOVA results showed that the mean values for diastolic blood pressure, fasting blood glucose, cholesterol, and BMI were significantly higher among subjects with $\geq 1$ risk factor. Lee et al. found similar results in their study [5]. Poulter found that other cardiovascular risk factors, including obesity, smoking, glucose intolerance, physical inactivity and dyslipidaemias often coexist with hypertension in both older and younger age groups [11]. He concluded that this 'clustering' of risk factors for cardiovascular disease has major implications for treatment thresholds and choice of antihypertensive therapy.

In Italy, Pasini et al. studied the clustering of different combinations of CVD risk factors (systolic and diastolic hypertension, total cholesterol, cigarette smoking and obesity) among nationals aged 40-59

البحلة الصحية لثرق المتوسط، منظمة الصحة العالمية، المخلد الثاسع، العلددان 0-7، ب +. 


\begin{tabular}{|c|c|c|c|c|c|c|}
\hline \multirow[t]{2}{*}{ Variable } & \multicolumn{2}{|c|}{$20-39$ years $(n=3367)$} & \multicolumn{2}{|c|}{$39-59$ years $(n=1479)$} & \multicolumn{2}{|c|}{$\geq 60$ years $(n=711)$} \\
\hline & $\begin{array}{l}\text { Adjusted } \\
\text { OR }\end{array}$ & $P$-value & $\begin{array}{c}\text { Adjusted } \\
\text { OR }\end{array}$ & $P$-value & $\begin{array}{l}\text { Adjusted } \\
\text { OR }\end{array}$ & $P$-value \\
\hline \multicolumn{7}{|l|}{ Place of residence } \\
\hline Urban $=0$ & - & - & - & - & - & - \\
\hline Rural = 1 & 0.81 & 0.028 & 0.75 & 0.014 & 0.66 & 0.013 \\
\hline \multicolumn{7}{|l|}{ Education level } \\
\hline Illiterate = $1(R C)$ & - & - & 1.00 & - & - & - \\
\hline$<$ Secondary $=2$ & - & - & 1.71 & $<0.001$ & - & - \\
\hline$\geq$ Secondary = 31 & - & - & 2.88 & $<0.001$ & - & - \\
\hline \multicolumn{7}{|l|}{ Sex } \\
\hline Male $=0$ & - & - & - & - & - & - \\
\hline Female $=1$ & 0.73 & $<0.001$ & 1.29 & 0.038 & 1.70 & $<0.001$ \\
\hline \multicolumn{7}{|l|}{ Marital status } \\
\hline Single $=1$ & 0.36 & $<0.001$ & - & - & - & - \\
\hline Divorced/separated = 2 & 1.66 & 0.027 & - & - & - & - \\
\hline Widowed = 3 & 0.80 & 0.673 & - & - & - & - \\
\hline Married $=4(\mathrm{RC})$ & 1.00 & & - & - & - & - \\
\hline
\end{tabular}

The total number of subjects in the study was 7011, of whom 5660 (81\%) completed the physical and laboratory measurements. However, the data of 3 subjects (0.05\% of 5660 subjects) were not entered in the logistic regression models due to missing data in some of the independent variables.

$R C=$ Reference category.

years [12]. When considering the prevalence of high SBP or DBP, high total cholesterol or cigarette smoking, he found that $72.3 \%$ of men and $67.7 \%$ of women had at least one of the main risk factors for coronary heart disease and usually higher values for SBP or DBP, whereas $29.3 \%$ of men and $21.2 \%$ of women had $\geq 2$ factors. In our study, where the clustering of DBP, diabetes, overweight/obesity, and high fasting serum cholesterol was investigated, it was found that $72 \%$ of the total sample (aged $\geq 20$ years) had $\geq 1$ risk factor and $37.2 \%$ had $\geq 2$ risk factors, a higher prevalence than reported in the Pasini study, despite that study's different clustering set and limited age group selection, which would be expected to increase rather than reduce prevalence.

Campos-Outcalt et al. studied another set of CVD risk factors (diabetes, hypertension, hypercholesterolaemia, obesity and smoking) clustering in a different age group among 230 Native Americans from a south-western tribe aged 25-65 years [13]. They found that $86 \%$ of the participants had $\geq 1$ risk factor and $52 \%$ had $\geq 2$ risk factors. The difference in results between this and our study can be explained by the different clustering set, the very large difference in sample size and the ethnic specificity of Native Americans, who were not a representative sample of the wider population of the United States of America. 
Because of the importance of the clustering of CVD risk factors, Mancia concluded that the established major risk factors for CVD, hypertension, hypercholesterolaemia and smoking, are present, often in combination, in populations around the world [14]. He added that these factors have been found to interact in a synergistic manner to increase the risk of coronary heart disease. Mancia therefore, suggested that traditional antihypertensive treatments offered little protection against coronary heart disease, perhaps because antihypertensive drugs tend to be prescribed to reduce BP without taking account of the presence of other risk factors. However, it should be borne in mind that the Mancia study was conducted over 15 years ago (1988), and newer antihypertensive medications are increasingly targeting the cooccurrence of hypertension and other CVD risk factors.

Phillips et al. concluded that diabetic patients have a higher prevalence of CVD risk factors than those without diabetes, therefore requiring improved vigilance of diabetic patients and interventions to modify the associated risk factors [15]. Bog-Hansen et al. similarly reported a strong coexistence of hypertension and type 2 diabetes [16].

Regarding the demographic and social factors significantly associated with clustering in the present study, smoking was not significantly associated and is not shown in the logistic regression models in Table 3 and Table 4. Salgado-Sales found results similar to those in our study. He found that in Acapulco, Mexico, among 1011 women and 1001 men aged $\geq 20$ years, the average levels of serum cholesterol were higher in older, overweight, hypertensive individuals and that the differences were statistically significant, but there was no difference in the choles- terol levels of individuals with tobacco smoking habits [17].

In our study, urban residence was significantly associated with clustering of CVD risk factors in the overall sample, in the male and female subsamples and in the different age group sub-samples, although this association was not statistically significant with each of the individual risk factors per se (data not shown). This is not necessarily contradictory. As el Mugamer et al. have previously observed for the United Arab Emirates, which has a similar culture to that of Oman, as socioeconomic development in the region intensifies, the difference in lifestyles between urban and rural residents is becoming increasingly blurred [18]. Abdul-Rahim et al. concluded that although no significant differences were found in the prevalence of hypertension and diabetes between urban and rural populations, other components of metabolic syndrome, namely elevated triglycerides, low HDL cholesterol and overall obesity were more prevalent in the urban population [19].

While being female gender was a protective factor in the younger 20-39-yearold age group ( $\mathrm{OR}=0.73, P<0.05)$, it increased the clustering risk in the higher age groups, i.e. the 40-59-year-olds and those aged $\geq 60$ years, where females were 1.3 and 1.7 times respectively more likely to have clustering than males in these age groups. This may be explained by the protective role of female sex hormones before the age of 40 years.

Having attained a higher level of education was protective for the female subsample $(\mathrm{OR}=0.698, P<0.05)$, while males who had attained a secondary education or above were 1.87 times more likely to have aggregated risk factors. This cannot be explained by the relatively young age of highly educated females in Oman, as the

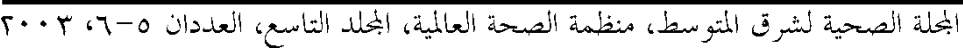


OR was already age-adjusted for both genders. It could be explained by other psychosocial factors that should be addressed in future studies.

\section{Conclusion and recommendations}

Both diabetes mellitus and hypertension are important public health problems in Oman. There needs to be a heightening of the level of awareness among primary care physicians to be alert to the possible presence of these pathologies among their patients. General community awareness also needs to be raised about individual risk factors for diabetes and hypertension, and about their aggregated effect in the development of CVD.

Improving understanding and awareness among physicians and the general community will aid prevention, diagnosis and management of both diabetes and hypertension, and in turn CVD, and can potentially lead to a reduction in complications arising from these chronic conditions. Disseminating to physicians the results shown in the logistic regression models of those factors significantly associated with clustering will aid in their ability to predict the presence of clustering and prompt them to more closely monitor patients at risk. This will lead to more efficient registration and management of chronic diseases at the primary care level.

Medical practitioners should always suspect clustering of CVD risk factors in patients who are aged $\geq 40$ years, married and living in an urban setting. Having an urban place of residence was a common risk factor in all models used in this study.

Improving community awareness of the problem by health education campaigns is essential if the prevalence of CVD risk factors and the burden of CVD in the general population are to be reduced. Patient education and a coordinated approach by physicians, nurses and other healthcare providers in a multidisciplinary approach to the treatment of obese patients are also of fundamental importance to reduce the prevalence of CVD in the population. Abdominal obesity is the earliest symptom of metabolic cardiovascular syndrome. Prevention or early treatment of such obesity can prevent or delay the onset of diseases associated with the syndrome. Vigilance and effecting positive behavioural change, not always easily achieved, are key factors in the prevention, early diagnosis, and reduced complications of risk factors leading to CVD.

\section{References}

1. Asfour AG et al. Diabetes mellitus in the Sultanate of Oman. Diabetic medicine, 1991, 8:76-80.

2. Ghannem $\mathrm{H}$, Fredj $\mathrm{AH}$. Prevalence of cardiovascular risk factors in the urban population of Soussa in Tunisia. Journal of public health medicine, 1997, 19:3926.

3. Prevalence of cardiovascular disease risk-factor clustering among persons aged $>$ or $=45$ years - Louisiana, 19911995. Morbidity and mortality weekly report, 1997, 46:585-8.

4. McLaughlin T, Reaven G. Insulin resistance and hypertension. Patients in double jeopardy for cardiovascular disease. Geriatrics, 2000, 55:28-32, 35.

5. Lee ZS et al. Obesity is the key determinant of cardiovascular risk factors in the Hong Kong Chinese population: cross- 
sectional clinic-based study. Hong Kong medical journal, 2000, 6:13-23.

6. Bener A et al. Acanthosis nigricans, hyperinsulinaemia and risk factors for cardiovascular disease. Eastern Mediterranean health journal, 2000, 6:41624.

7. Musaiger AO, al-Roomi KA. Prevalence of risk factors for cardiovascular diseases among men and women in an Arab Gulf community. Nutrition and health, 1997, 11:149-57.

8. Ibrahim $\mathrm{MM}$ et al. Cardiovascular risk factors in normotensive and hypertensive Egyptians. Journal of hypertension, 2001, 9:1933-40.

9. Definition, diagnosis and classification of diabetes mellitus and its complications. Part 1: Diagnosis and classification of diabetes mellitus, a report of a WHO consultation. Geneva, World Health Organization, Department of Noncommunicable Disease Surveillance, 1999.

10. Annual Health Report, 2000. Muscat, Oman Ministry of Health, 2001:9-61.

11. Poulter NR. Risk factors for cardiovascular disease: 'clustering' in the older hypertensive man. British journal of clinical practice, 1994, 74(suppl.):4-7.

12. Pasini GF et al. Prevalence of risk factors for coronary heart disease in a mountain community in northern Italy. Giornale Italiano di cardiologia, 1999, 29:891-7.
13. Campos-Outcalt $D$ et al. Prevalence of cardiovascular disease risk factors in a southwestern Native American tribe. Public health reports, 1995, 110:742-8.

14. Mancia G. The need to manage risk factors of coronary heart disease. American heart journal, 1988, 115:240-2.

15. Phillips $P$ et al. Cardiovascular risk factors in South Australians with diabetes. Australian journal of public health, 1994, 18:445-9.

16. Bog-Hansen E et al. Risk factor clustering in patients with hypertension and non-insulin-dependent diabetes mellitus. The Skaraborg Hypertension Project. Journal of internal medicine, 1998, 243:223-32.

17. Salgado-Sales P. Estudio epidemiologico de colesterol en poblacion de Acapulco, Mexico. [An epidemiological study of cholesterol in the population of Acapulco, Mexico]. Salud publica di Mexico, 1992, 34:653-9.

18. el Mugamer IT et al. Diabetes, obesity and hypertension in urban and rural people of bedouin origin in the United Arab Emirates. Journal of tropical medicine and hygiene, 1995, 98:407-15.

19. Abdul-Rahim HF. The metabolic syndrome in the West Bank population: an urban-rural comparison. Diabetes care, 2001, 24:275-9.

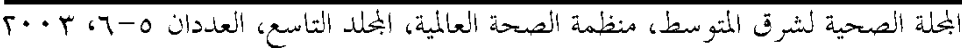

